\title{
Does Microwave Ablation of the Tumor Edge Allow for Joint-sparing Surgery in Patients With Osteosarcoma of the Proximal Tibia?
}

\author{
Jing Li MD, PhD, Zheng Guo MD, PhD, Zhen Wang MD, \\ Hongbin Fan MD, Jun Fu MD
}

Received: 18 February 2015/ Accepted: 30 June 2015/Published online: 8 July 2015

(C) The Association of Bone and Joint Surgeons (R 2015

\begin{abstract}
Background Joint-sparing surgery of a patient's native joint for osteosarcoma likely affords better function and comparable survival. However, it sometimes is challenging to resect a juxtaarticular osteosarcoma in a way that preserves the affected epiphysis because wide margins are necessary to minimize the risk of local recurrence. If there was a method to resect a tumor close to the joint and treat a potentially positive margin to prevent recurrence, it might allow salvage of a joint that otherwise might be lost. Questions/purposes We therefore asked (1) whether joint-preserving tumor resection could be performed for
\end{abstract}

Each author certifies that he or she, or a member of his or her immediate family, has no funding or commercial associations (eg, consultancies, stock ownership, equity interest, patent/licensing arrangements, etc) that might pose a conflict of interest in connection with the submitted article.

All ICMJE Conflict of Interest Forms for authors and Clinical Orthopaedics and Related Research ${ }^{\mathbb{R}}$ editors and board members are on file with the publication and can be viewed on request.

Clinical Orthopaedics and Related Research ${ }^{\mathbb{B}}$ neither advocates nor endorses the use of any treatment, drug, or device. Readers are encouraged to always seek additional information, including FDAapproval status, of any drug or device prior to clinical use.

Each author certifies that his or her institution approved the human protocol for this investigation, that all investigations were conducted in conformity with ethical principles of research, and that informed consent for participation in the study was obtained.

J. Li (凹), Z. Guo, Z. Wang, H. Fan, J. Fu

The Orthopaedic Department, Xijing Hospital Affiliated to the

Fourth Military Medical University, Xi'an 710032,

People's Republic of China

e-mail: ljfmmu@sina.com juxtaarticular osteosarcoma after microwave ablation of the tumor edge under navigation without leading to local recurrences, (2) what is the resulting function, and (3) what are the complications associated with this procedure.

Methods Between 2009 and 2011, we treated 11 patients who had juxtaarticular osteosarcoma of the proximal tibia (mean age, 12 years; range, 9-16 years) with joint-preserving surgery by transepiphysis tumor resection after navigation-assisted microwave ablation of the tumor edge; they were followed a minimum of 37 months (mean, 48 months; range 37-62 months), and none was lost to followup. Patients were considered eligible for this procedure if they had a distance from the tumor edge to the articular surface between 10 to $15 \mathrm{~mm}$, good chemotherapy responses, no pathologic fracture and no tumor involvement of major neurovascular structures. Allograft in combination with a vascularized fibula flap was used for segmental reconstruction. We recorded local tumor control, complications, and functional outcomes using the Musculoskeletal Tumor Society score, which ranges from 0 to 30, with higher scores indicating better function.

Results There were no local recurrences. Major complications included osteonecrosis of part of the epiphysis in two patients and deep infection in one. The Musculoskeletal Tumor Society score ranged from 26 to 30 with a mean of 29.

Conclusions In selected patients with osteosarcoma invading the epiphysis, navigated resection facilitates performing joint-sparing surgery, and in our small series, the adjuvant microwave ablation seemed to provide adequate local tumor control. Although more experience and longer followup are needed, this approach may make it possible to salvage more native joints when performing limb salvage for osteosarcoma.

Level of Evidence Level IV, therapeutic study. 


\section{Introduction}

Advancement in chemotherapy and reconstructive techniques has made it possible for the majority of patients with osteosarcoma to undergo successful limb salvage surgical procedures $[7,16]$. For juxtaarticular osteosarcoma, this usually results in large segmental resections with extensive bone sacrifice followed by reconstruction with a megaprosthetic implant or osteoarticular allograft. However, these reconstruction techniques are associated with frequent complications [2, 3, 22].

Historically, there have been attempts to improve contiguous joint function and decrease prosthesis-related complications by means of an intercalary resection, preserving a part or all of the joint surface. Intercalary resection may result in superior joint function and longevity because of preservation of normal articular cartilage and because ligamentous stability is preserved [20, 23, 28]. Such a procedure was made possible by understanding the epiphyseal spread of tumor with reference to the articular surface [15, 26, 28]. Despite controversy [15, 17, 26], it generally is agreed that the joint surface-saving method can be safely used only in patients who have a tumor that does not breach the epiphyseal line or extend to the subchondral region [23, 28]. Given the high risk of local recurrence and catastrophic oncologic outcome with a contaminated margin, some orthopaedic oncologists are reluctant to perform a joint-saving procedure for patients with a tumor breaking through the epiphyseal growth plate because of an unreliable margin $[16,23]$.

Tumor ablation is defined as direct application of thermal or chemical therapies to a tumor to achieve eradication or tumor destruction. Microwave ablation is the most recent development in the field of tumor ablation [1, 4, 5, 8]. Electromagnetic microwaves agitate water molecules in the surrounding tissue, producing friction and heat, thus inducing cellular death through coagulation necrosis [24]. Microwave ablation has shown potential in the treatment of primary and secondary liver disease, lung malignancies, and renal tumors $[1,4,8]$. Early clinical use of microwave ablation in primary bone tumors and bone metastases has been promising $[5,11]$. During the last decade, we performed joint-preservation surgery for patients with juxtaarticular osteosarcoma by transepiphyseal osteotomy after navigation-assisted microwave ablation of the edge of the tumor and reconstruction with an intercalary biologic reconstruction, preserving the native joint and maintaining a nearly normal joint.

We reviewed our experience with this procedure by asking (1) whether joint-preserving tumor resection could be performed for juxtaarticular osteosarcoma after microwave ablation of the tumor edge under navigation without leading to local recurrences, (2) what is the resulting function, and (3) what are the complications associated with this procedure?

\section{Patients and Methods}

Between 2009 and 2011, we treated 11 patients who had been treated for juxtaarticular osteosarcoma in the proximal tibia by microwave ablation-aided joint preserving surgery. There were six boys and five girls with a mean age of 12 years (range, 9-16 years) in this series. They were followed a minimum of 37 months (mean, 48 months; range, 37-62 months), and none was lost to followup. All had Stage IIB tumors according to the Musculoskeletal Tumor Society (MSTS) staging system [9]. All patients in this study met the following criteria: (1) the distance between the tumor edge and articular surface was between 10 to $15 \mathrm{~mm}$ on a T1-weighted coronal MR image; (2) there was no obvious soft tissue mass extension that invaded the major neurovascular bundle; (3) there was no pathologic fracture; and (4) there was good response to neoadjuvant chemotherapy. During the study period, there were 12 patients who potentially were eligible for the new treatment. Among these patients, 11 underwent this treatment. The one patient who declined instead underwent intraarticular tumor resection and endoprosthetic replacement. The response of the tumor to chemotherapy was assessed at a multidisciplinary oncologic meeting. All data were obtained from medical records and radiographs.

\section{Surgical Procedures}

Surgical procedures were the same as for conventional partial epiphysis-preserving surgery [20, 23], except that before the osteotomies, navigation-aided microwave ablation of the proximal tumor edge was applied. Each operation was performed in three steps. First, we set up the navigation system and performed the image-to-patient registration. Second, under navigation, we identified the extent of the tumor and ablated the zone of the proximal tumor edge. Afterward, we performed an osteotomy at the edge of the tumor and removed the tumor. Approximately $1 \mathrm{~cm}$ of residual epiphysis was preserved. Third, we reconstructed the defect with the massive allograft bone in combination with a vascularized fibula bone graft.

We used the navigation method described by Li et al. [19]. CT images of the lesion with slices of $0.625 \mathrm{~mm}$ and MR images with slices of $2 \mathrm{~mm}$ were obtained. Image data sets were imported to a navigation system (Stryker ${ }^{\circledR} \mathrm{CT}$ spine navigation, version 1.6; Stryker ${ }^{\circledR}$ Corporation, Freiburg, 
Germany) for image fusion. The CT and MR images were fused by matching segmented known structures in corresponding MRI and CT data manually. The data sets of the fused images were transferred to the navigation system for the preoperative ablation plan. The tumor edge was determined at the transition of marrow signal from abnormal to normal on T1-weighted MR images. Areas of intermediate signal intensity adjacent to the tumor edge were regarded as part of the tumor. Preoperative image fusion was successful and all patient-to-image registrations were possible, with a mean error of $0.52 \mathrm{~mm}$ (range, $0.41-0.68 \mathrm{~mm}$ ). After appropriate surgical exposure, we placed a dynamic reference base at least $1 \mathrm{~cm}$ from the tumor margin distally but within the planned osteotomy site. Soft tissue dissection at the joint capsule or ligaments was minimized to preserve blood supply to the epiphysis. Patient-to-image registration was performed using the paired-point technique. After that, an operative drill and microwave antennae mounted with navigation trackers were calibrated to the navigation system. This allowed real-time tracking of the spatial location of the tip of drill or antennae in relation to the patient's anatomy on the virtual preoperative images. After distal tibia osteotomy, the tumor segment was separated from the surrounding normal tissues while keeping the major ligament of the knee intact (Fig. 1). The planned proximal osteotomy line was set at the edge of the tumor. Preoperative identification of epiphyseal tumor extension includes areas of intermediate signal intensity, which should be included in the ablation area (Fig. 2). With the aid of navigation, the antenna array was placed $3 \mathrm{~mm}$ distal to the predesigned osteotomy line for microwave hyperthermia of the tumor edge (Fig. 3). We placed two to five antennae in the tumor, $1 \mathrm{~cm}$ apart, according to the shape and size of the tumor edge so that the tumor edge could be ablated adequately. The tumor was ablated with direct heating while normal soft tissues were protected from overheating. The core temperature reached $108^{\circ} \mathrm{C}$ and the normal tissue temperature remained less than $39^{\circ} \mathrm{C}$. We put needles into the knee cavity for continuous perfusion of cold saline to keep the articular cartilage and its subchondral bone from overheating. The output power from microwave generators with $2450 \mathrm{MHz}$ frequency was set at $60 \mathrm{~W}$. During ablation, we usually ablate 3 minutes in one place. After that, the antenna is withdrawn $2 \mathrm{~cm}$ (because the length of the microwave generator in the antenna is $2 \mathrm{~cm}$ ) and ablation is started for another 3 minutes so that the tumor around the channel could be ablated completely without tumor seeding. The antenna is withdrawn in this way until the entire length of the channel is ablated.

We then performed the proximal osteotomy with the aid of navigation. The location of the osteotome in relation to the tumor edge was checked in three dimensions. The tumor was resected en bloc. The tumors were sectioned longitudinally at $5 \mathrm{~mm}$ thickness. The blocks containing the margins of resection were secured. All the tissue blocks

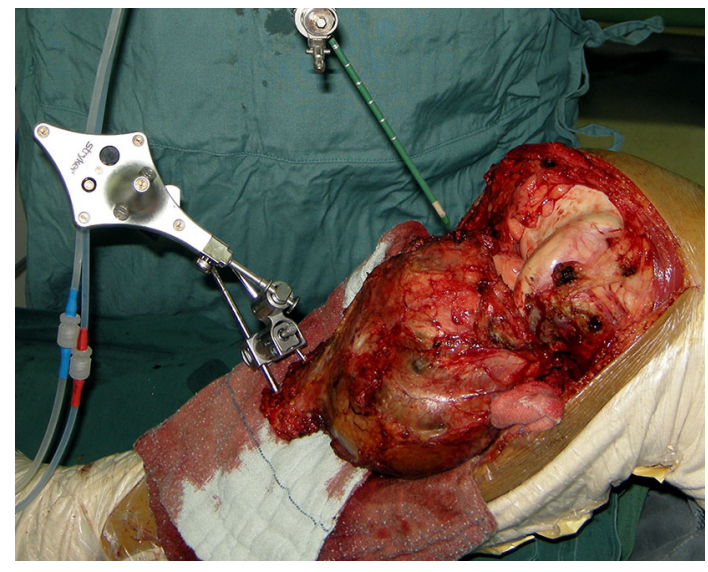

Fig. 1 The reference base tracker was fixed approximately $1 \mathrm{~cm}$ proximal to the distal osteotomy line and facilitated microwave ablation by allowing continuous navigational monitoring.

were evaluated histologically for tumor hyperthermia necrosis. The eschar resulting from the heat necrosis at the osteotomy section appeared in the majority of the specimens (Fig. 4). Histologic examination of all resected specimens showed that part of the proximal margins were histologically negative and part of the margins were necrotic. The average thickness of the preserved epiphysis was $11 \mathrm{~mm}$ (range, $8-13 \mathrm{~mm}$ ). The distance between the osteotomy line and the antenna ranged from 3 to $6 \mathrm{~mm}$. After tumor removal, massive allograft in combination with an ipsilateral transferred pedicled fibular graft was used for reconstruction (Fig. 5), which was described in a previous study [18].

Single-photon emission CT was used to evaluate the viability of the preserved epiphysis and transferred fibula at 1 week postoperatively and to detect tumor relapse in the residual epiphysis every 6 months thereafter. We encouraged patients to do active knee flexion and extension 3 weeks postoperatively. The patients were allowed partial weightbearing for early activity 3 months postoperatively. All patients were followed up at 1 month, 3 months, every 3 months for 2 years, every 6 months until 3 years, and annually thereafter. We obtained AP and lateral radiographs of the surgically treated area to evaluate bone union and growth arrest. Full-length standing radiographs were obtained to evaluate the leg length differences. We also performed clinical examinations to look for local relapse. Signs of bony union were evaluated by serial sets of plain radiographs. The overall mean time for bone union was 7 months (range, 5-11 months) at the proximal allografttibia junction and 14 months (range, 10-18 month) at the distal allograft-tibia junction. Lower extremity function was evaluated by measuring MSTS scores [10], which range from 0 to 30 , with higher scores indicating better function. All patients were followed up by the chief 


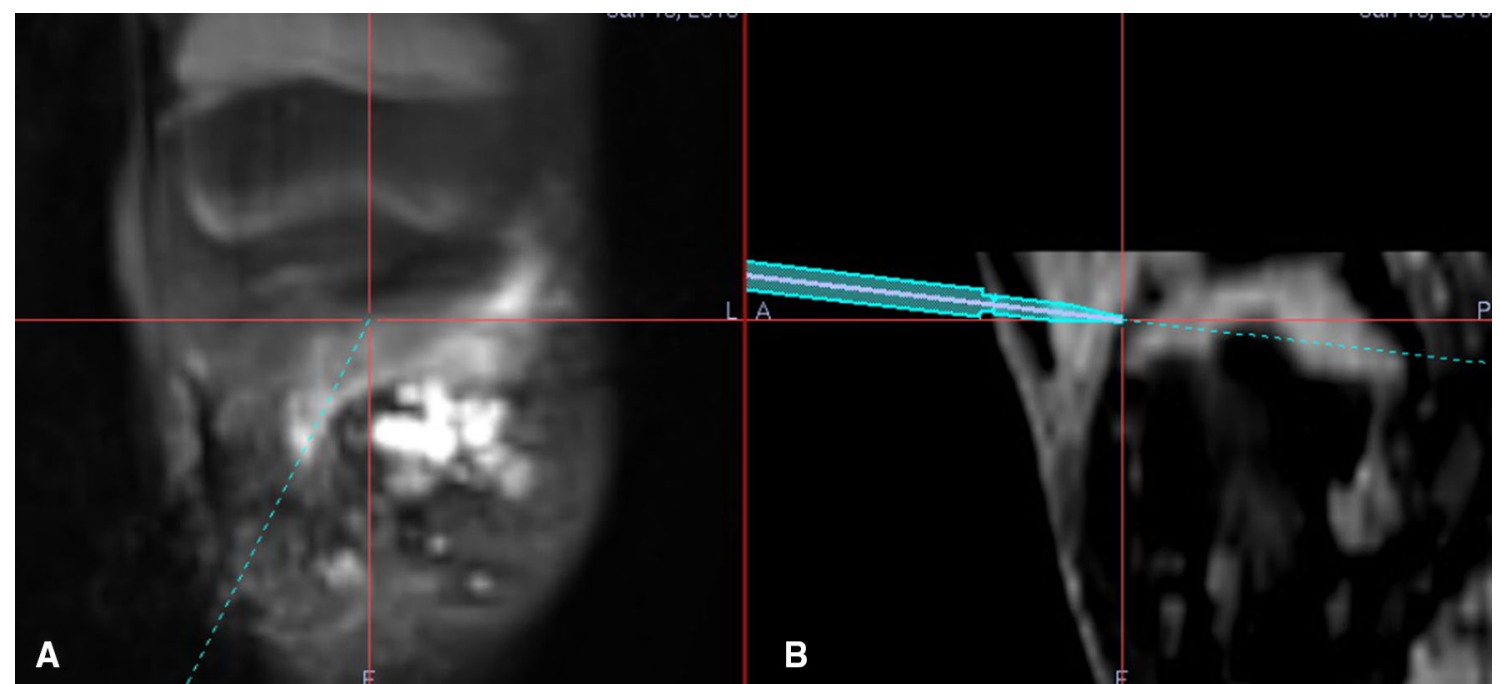

Fig. 2A-B The navigation monitor shows (A) coronal and (B) sagittal images for intraoperative guidance. The microwave ablation antenna was placed toward the edge of the tumor.
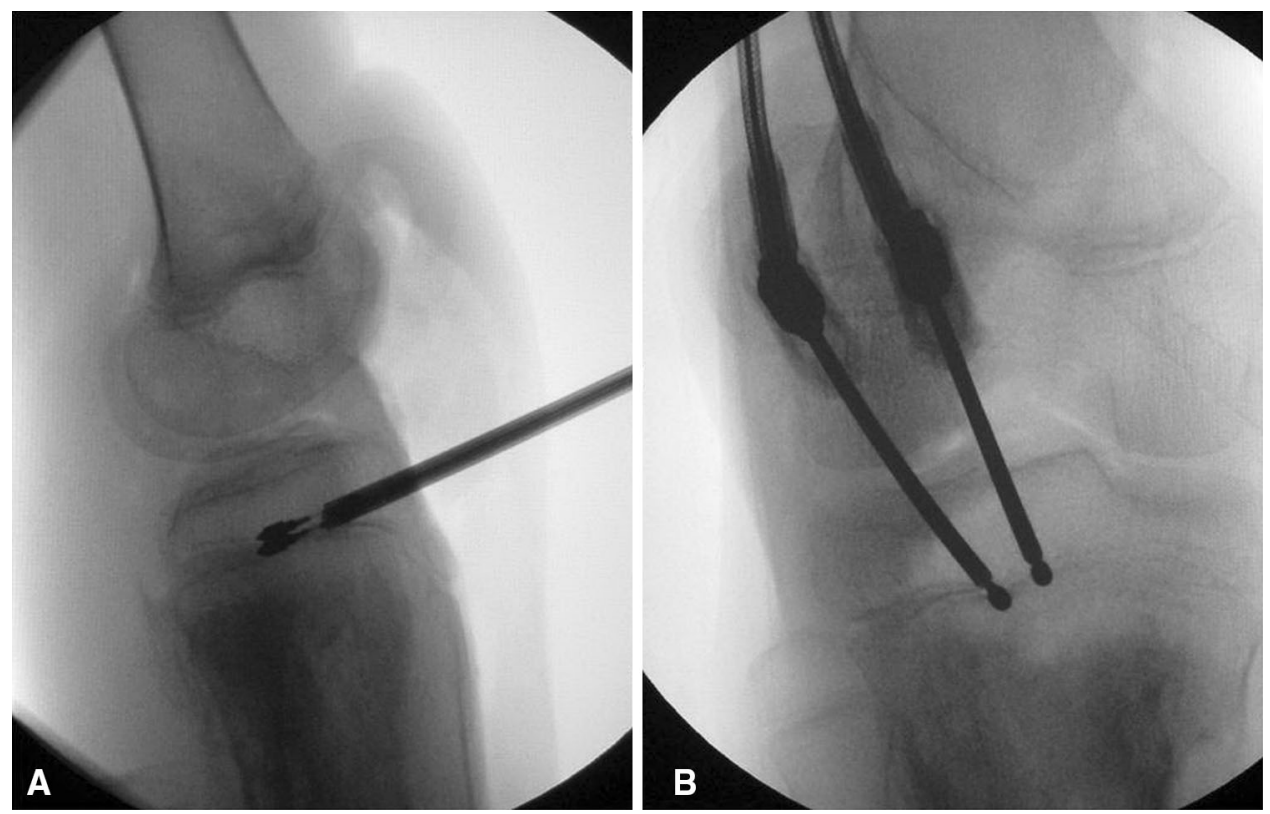

Fig. 3A-B Intraoperative (A) AP and (B) lateral radiographs show the position of the microwave ablation antenna and its relationship to the growth plate.

surgeon (JL). ROM of the knee was measured using a goniometer and recorded at every visit.

\section{Results}

None of the patients in this series had local recurrence. Two of 11 patients (18\%) had pulmonary metastases develop. One underwent excision of the metastasis and survived without evidence of disease. The other died of the pulmonary disease.
The mean MSTS functional score of the patients was 29 points (range, 26-30 points) at the final followup. Postoperative rehabilitation was uneventful in all patients. The mean active ROM of the knee was $116^{\circ}$ (range, $95^{\circ}-$ $135^{\circ}$ ). All patients could walk without an aid. The mean time from the date of initial surgery to full weightbearing without restrictions was 13 months (range, 8-18 months).

Three patients with four complications were treated nonoperatively: two with clawed toes; one with peroneal nerve palsy, which resolved completely 4 months postoperatively; and one patient had knee instability secondary to 


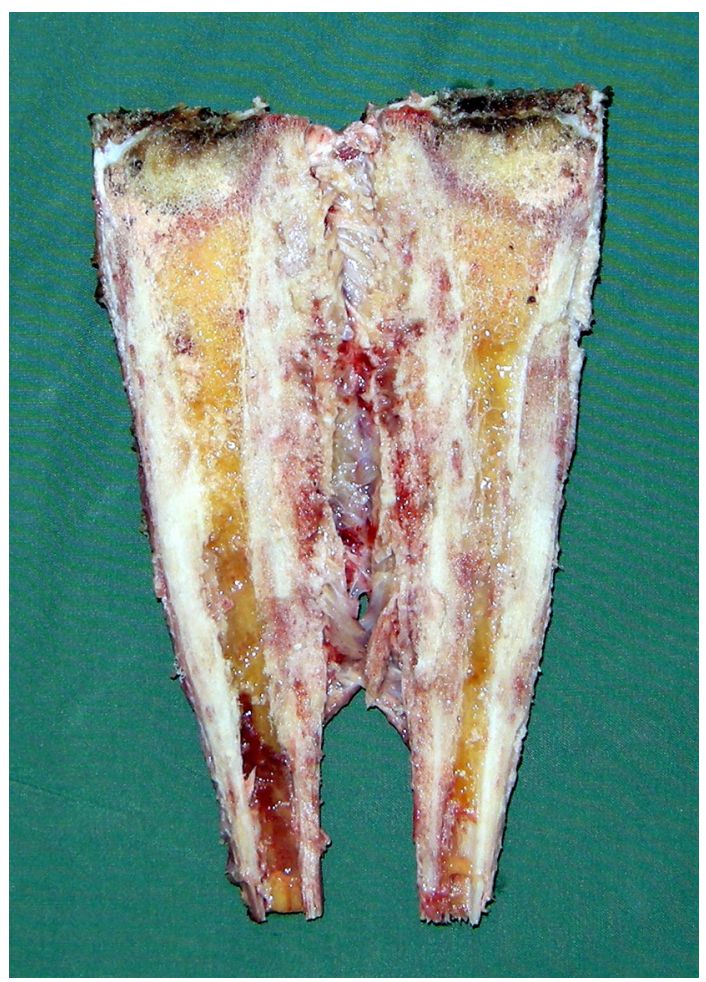

Fig. 4 The gross pathology specimen shows that the tumor was excised with the eschar (black portion) resulting from heat necrosis at the proximal osteotomy section.

medial collateral ligament rupture resulting from a postoperative sport injury that was treated successfully with cast immobilization. Marginal necrosis of the skin that required débridement occurred in one patient. One patient had a deep infection develop 15 months postoperatively, which resolved after antibiotics, débridement, and covering the area with a rectus femoris flap. Bone scans showed that the fibula flaps and remaining epiphysis were viable except for osteonecrosis of part of the residual epiphysis in two of the patients. They had no clinical symptoms. Patients with an open physis before surgery experienced growth arrest of the affected proximal tibia, with a mean shortening of 1.9 $\mathrm{cm}$ (range, 0.8-3.1 cm) compared with the unaffected side (Fig. 6). Limb length was determined by scanograms. Limb length discrepancy clinically was negligible in all patients in whom it did not exceed $1 \mathrm{~cm}$. In two patients discrepancies greater than $1.5 \mathrm{~cm}$ were satisfactorily compensated by a shoe lift (Table 1).

\section{Discussion}

There have been attempts to improve joint function in patients with osteosarcoma by performing an intercalary resection that preserves the native joint $[15,17,23,28]$. However, this is not easy to do for a juxtaarticular
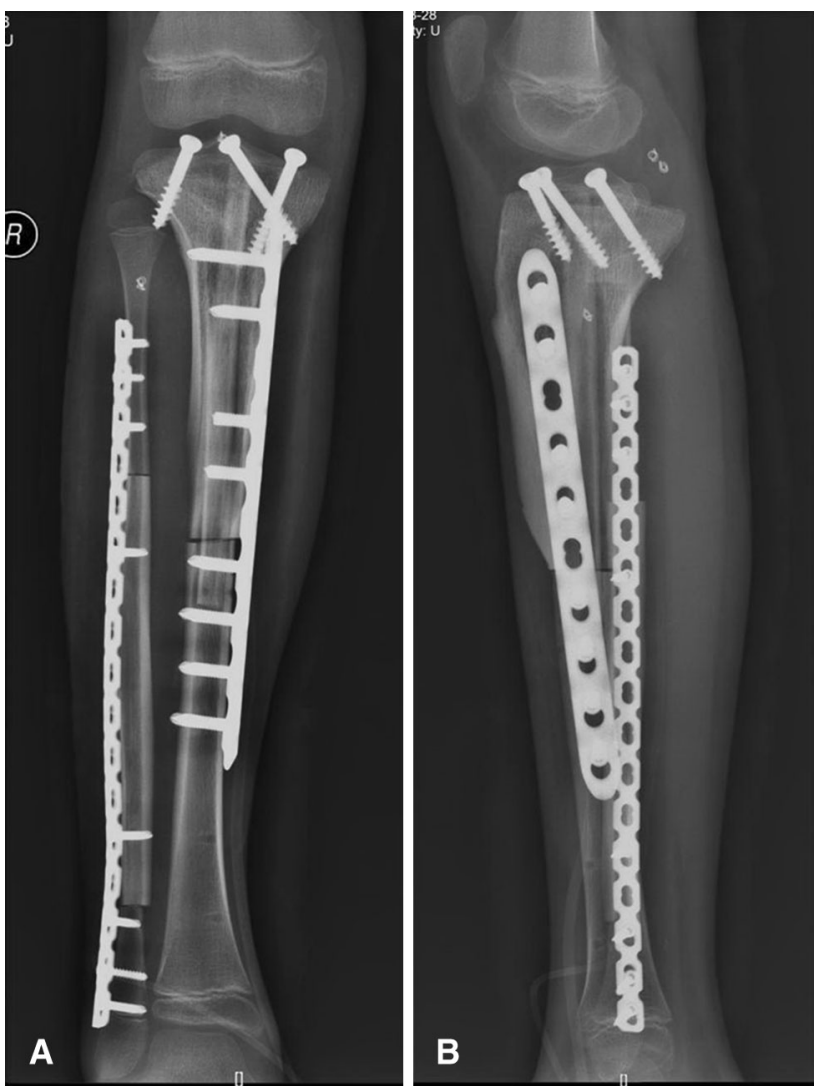

Fig. 5A-B (A) AP and (B) Lateral radiographs obtained 3 months postoperatively show the ipsilateral vascularized fibula flap was transferred to contact with the residual epiphysis.

osteosarcoma owing to possible residual tumor if the tumor is close to the articular surface. It may be necessary to develop a local adjunctive treatment that has marked effects on the tumor edge, thus enabling a surgical margin that is as safe as with a wide resection and preserving as much epiphysis as possible. However, we do not have the tools to allow us do this. Although heat ablation by microwave is a potential tool, there is a paucity of literature regarding its use in joint-saving surgery [11]. Therefore, we used a microwave to ablate the tumor edge close to the joint making an intercalary resection possible in patients with juxtaarticular osteosarcoma in which the distance between the tumor edge and articular cartilage ranged from 10 to $15 \mathrm{~mm}$. We therefore sought to assess whether jointpreserving tumor resection could be performed for juxtaarticular osteosarcoma after microwave ablation of the tumor edge under navigation without leading to tumor relapse in the remaining epiphysis.

Certain limitations of this study require consideration. First, this study has a small number of patients and no control group therefore, we could not do a comparative assessment of our clinical results with those of wide resection alone or other methods of treating margins such as the argon beam. The resection margin in our series was 


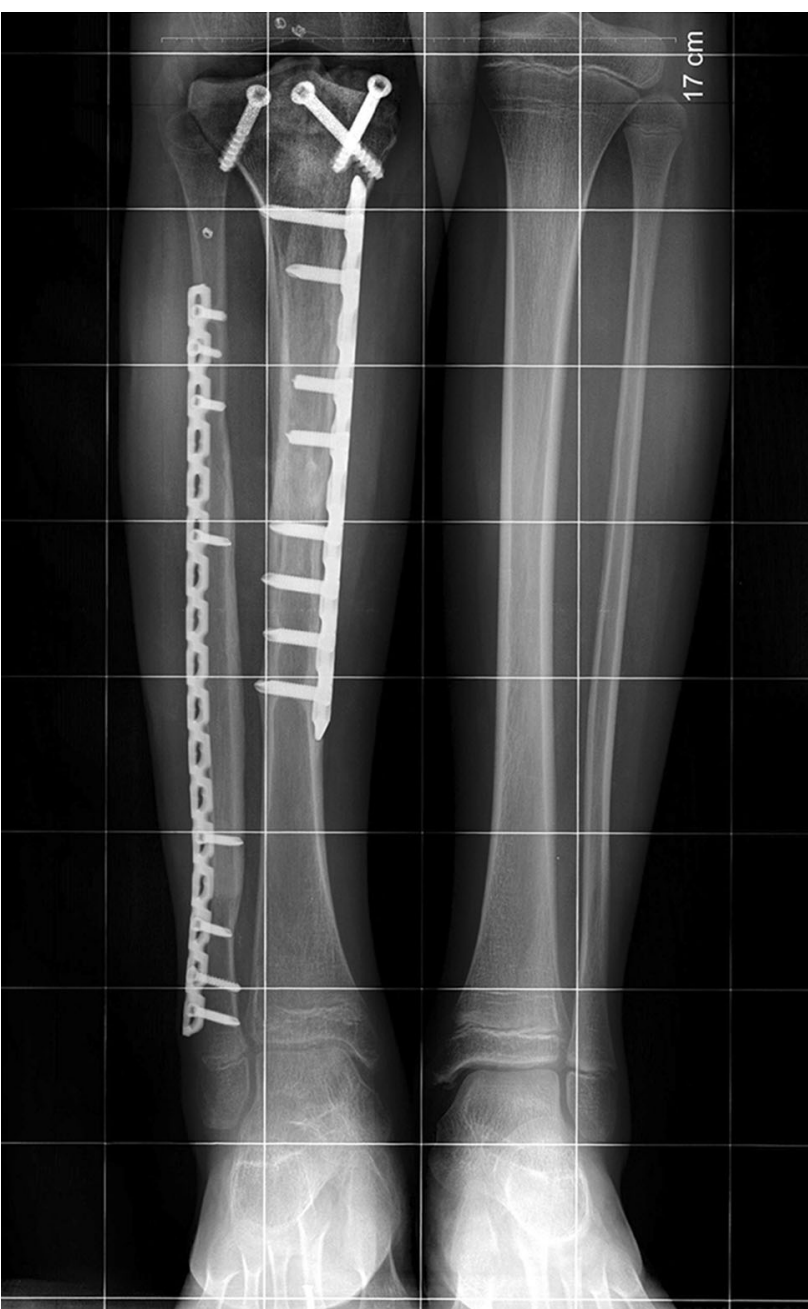

Fig. 6 At the 42-month followup, the patient's radiograph shows the bone union achieved at every junction. The surgically treated side had growth arrest at the proximal tibia and an obvious tibial discrepancy.

considered necrotic margins, which are difficult to classify by modern oncologic parameters for the treatment of osteosarcoma. Second, although the risk of local recurrence is going to be low at 3 years, there is still some risk which may be evident with longer followup. A minimum of 5 years followup is needed to be more certain of its safety. Third, there has been no consensus regarding appropriate time and energy of microwaves which balance the intensity of ablation needed to adequately destroy the tumor and retain the viability of the remaining epiphysis. Therefore, investigations should be done to determine the appropriate temperature and duration of microwave ablation to sterilize the tumor and to minimize the thermal damage to the remaining epiphysis.

In our series, no patient had local tumor recurrence, which indicates joint-preserving surgery using a combination of adjuvant microwave ablation and tumor resection may be a viable and safe option for selected patients with juxtaarticular sarcoma. Early histologic studies [13, 25] of resected specimens and an imaging study [12] have suggested that the prevalence of transepiphyseal spread of the tumor in metaphyseal osteosarcomas is approximately $80 \%$. Some orthopaedic surgeons would prefer treating osteosarcoma penetrating the growth plate by removing the entire epiphysis with the tumor to ensure adequate margins unless the joint is contaminated with tumor, in which case an extraarticular resection is preferred [21, 22, 28]. However, subsequent replacement with a tumor prosthesis or osteoarticular allograft is associated with uncertain durability of the reconstruction and the longevity of these limb salvage procedures is unlikely to last the lifetime of the patient [3, 22]. Navigation that applies computer-based image processing of MR image information to intraoperative observation and guidance has been used in bone tumor surgery $[6,14,27]$. This enables the surgeon to better understand the edges of tumors and make a tumor-free osteotomy possible during the surgery. Therefore, with the aid of MRI-based intraoperative navigation, transepiphyseal osteotomy with preservation of a thin layer of articular cartilage and subchondral bone could be performed in patients with the tumor extending to or beyond the physeal cartilage, preserving $1 \mathrm{~cm}$ of normal epiphysis. Li et al. [17] suggested use of a navigation system may help identify tumor extent accurately at surgery. Despite the accuracy of navigation making precise tumor resection possible, we believe patients undergoing the joint-saving procedure are still at risk for unreliable margins when the distance between the edge of the tumor and osteotomy line is less than $1.5 \mathrm{~mm}$, owing to registration errors of the navigation and/or discrepancies between the MRI signal and the actual tumor limits. Therefore, if the distance between the edge of the tumor and the articular cartilage was between 10 to $15 \mathrm{~mm}$, it is a challenge for the surgeon to preserve at least $1 \mathrm{~cm}$ thickness of the epiphysis even if with the aid of navigation. Microwave ablation has been used for palliative treatment for patients with painful bone metastases. To the best of our knowledge, only Fan et al. [11] reported on the use of microwave ablation in limb-sparing procedures. In their study, a combination of microwave ablation therapy and limb-sparing procedures in 134 patients with malignant bone tumors of the extremities showed a survival rate of $74 \%$. None of our patients experienced local relapse suggesting that microwave heat ablation is a potential useful adjuvant for juxtaarticular osteosarcomas.

The functional results of our series, with a mean MSTS score of 29 , were comparable to results of a study in which patients with partial epiphyseal preservation and allograft reconstruction had a mean MSTS score of 27 [23]. Sparing the articular end of the affected bone enables patients to retain their native joints and ligaments that in turn afford better proprioception and more normal joint function after reconstruction. The functional results in our series may be 
Table 1. Demographic data for 11 patients

\begin{tabular}{|c|c|c|c|c|c|c|c|c|c|c|}
\hline Patient & $\begin{array}{l}\text { Age } \\
\text { (years) }\end{array}$ & $\begin{array}{l}\text { Followup } \\
\text { (months) }\end{array}$ & $\begin{array}{l}\text { Resection } \\
\text { length } \\
(\mathrm{mm})\end{array}$ & $\begin{array}{l}\text { Necrosis of the } \\
\text { residual } \\
\text { epiphysis }\end{array}$ & $\begin{array}{l}\text { Discrepancy } \\
\text { of tibia }(\mathrm{cm})\end{array}$ & $\begin{array}{l}\text { Limb } \\
\text { discrepancy } \\
(\mathrm{cm})\end{array}$ & $\begin{array}{l}\text { Oncologic } \\
\text { results }\end{array}$ & $\begin{array}{l}\text { MSTS } \\
\text { score }\end{array}$ & Complications & $\begin{array}{l}\text { Additional } \\
\text { procedure }\end{array}$ \\
\hline 1 & 10 & 37 & 13 & No & -1.8 & 1 & $\mathrm{CDF}$ & 27 & $\begin{array}{l}\text { Skin necrosis; } \\
\text { infection }\end{array}$ & $\begin{array}{l}\text { Musculocutaneous } \\
\text { flap transfer }\end{array}$ \\
\hline 2 & 13 & 38 & 10 & Incomplete & 0 & None & $\mathrm{CDF}$ & 26 & $\begin{array}{l}\text { Knee } \\
\text { instability }\end{array}$ & $\begin{array}{l}\text { Knee brace } \\
\text { immobilization }\end{array}$ \\
\hline 3 & 9 & 44 & 8 & No & -3.1 & 1.9 & $\mathrm{CDF}$ & 29 & None & None \\
\hline 4 & 12 & 45 & 14 & Incomplete & -0.8 & None & DOD & 28 & $\begin{array}{l}\text { Lung } \\
\text { metastasis }\end{array}$ & None \\
\hline 5 & 10 & 47 & 11 & No & -2.3 & 1 & $\mathrm{CDF}$ & 30 & None & None \\
\hline 6 & 11 & 49 & 10 & No & -2.1 & 1.6 & $\mathrm{CDF}$ & 29 & $\begin{array}{l}\text { Peroneal } \\
\text { nerve palsy }\end{array}$ & None \\
\hline 7 & 14 & 49 & 15 & No & 0 & None & NED & 29 & $\begin{array}{l}\text { Lung } \\
\text { metastasis }\end{array}$ & $\begin{array}{l}\text { Pulmonary } \\
\text { lobectomy }\end{array}$ \\
\hline 8 & 16 & 50 & 16 & No & 0 & None & $\mathrm{CDF}$ & 29 & None & None \\
\hline 9 & 12 & 55 & 12 & No & -1.5 & 1 & $\mathrm{CDF}$ & 29 & None & None \\
\hline 10 & 14 & 56 & 11 & No & 0 & None & $\mathrm{CDF}$ & 30 & Claw toes & None \\
\hline 11 & 15 & 62 & 14 & No & 0 & None & $\mathrm{CDF}$ & 28 & $\begin{array}{l}\text { Wound } \\
\text { dehiscence }\end{array}$ & Débridement \\
\hline
\end{tabular}

MSTS = Musculoskeletal Tumor Society; CDF = continuously disease free; NED = no evidence of disease; DOD = died of disease.

attributed to preservation of a stable periarticular structure and optimal bony construct. Nonunion between residual epiphysis with a necrotic osteotomy surface and the avascular allograft is one of the reconstructive concerns. To increase the chance of bone union, we added the vascularized fibular flap during reconstruction and it seemed to be effective in prompting bone healing.

Our patients had few complications with this approach. Osteonecrosis of part of the epiphysis owing to heat damage was observed in two patients, and this is a potentially severe complication. Although the patients are asymptomatic at midterm followup, there still are risks of late symptomatic collapse with long-term followup. The growth plate was resected along with the tumor in the majority of patients; the preserved growth plate in the rest of the patients underwent heat necrosis. It is inevitable that longitudinal growth disturbances of the proximal tibia will develop in patients with an open physis. We did not use surgical lengthening or contralateral epiphysiodesis to equalize limb length discrepancy which was mild enough for the patients to use shoe lifts.

This technique has the potential to provide some unique contributions to joint-sparing surgery for juxtaarticular osteosarcoma; our study is intended to be exploratory to judge the value of the concept. With this approach, we believe we can maximize preservation of the epiphysis and assure a safe surgical margin in juxtaarticular osteosarcomas that would have been difficult to achieve without navigation and microwave ablation. Although our results are preliminary and based on a small number of patients without a control group, we believe the absence of local recurrence suggests this technique may be an appropriate option for select patients with high-grade bone tumors. Long-term followup in a larger series is needed to evaluate the clinical importance of the technique.

Acknowledgments We thank Yanjun Pei MD, Zhigang Wu MD, $\mathrm{PhD}$, and Fei Wang MD (digital orthopaedic team, Department of Orthopaedics, Xijing Hospital), for setup of the navigation system and support in using the navigation software; and Lei Shi MD, $\mathrm{PhD}$, Guojing Chen MD, and Haodong Zhu MD (Department of Orthopaedics, Xijing Hospital) for support with use of microwave ablation and documentation of operative procedures.

\section{References}

1. Abbas G, Schuchert MJ, Pennathur A, Gilbert S, Luketich JD. Ablative treatments for lung tumors: radiofrequency ablation, stereotactic radiosurgery, and microwave ablation. Thorac Surg Clin. 2007;17:261-271.

2. Baumgart R, Lenze U. Expandable endoprostheses in malignant bone tumors in children: indications and limitations. Recent Results Cancer Res. 2009;179:59-73.

3. Biau D1, Faure F, Katsahian S, Jeanrot C, Tomeno B, Anract P. Survival of total knee replacement with a megaprosthesis after bone tumor resection. J Bone Joint Surg Am. 2006;88:1285-1293.

4. Boutros C, Somasundar P, Garrean S, Saied A, Espat NJ. Microwave coagulation therapy for hepatic tumors: review of the literature and critical analysis. Surg Oncol. 2010;19:22-32.

5. Carrafiello G, Laganà D, Pellegrino $\mathrm{C}$, Fontana $\mathrm{F}$, Mangini $\mathrm{M}$, Nicotera $\mathrm{P}$, Petullà $\mathrm{M}$, Bracchi E, Genovese E, Cuffari S, Fugazzola C. Percutaneous imaging-guided ablation therapies in 
the treatment of symptomatic bone metastases: preliminary experience. Radiol Med. 2009;114:608-625.

6. Cho HS, Oh JH, Han I, Kim HS. Joint-preserving limb salvage surgery under navigation guidance. J Surg Oncol. 2009;100:227-232.

7. Chou AJ, Geller DS, Gorlick R. Therapy for osteosarcoma: where do we go from here? Paediatr Drugs. 2008;10:315-327.

8. Clark PE, Woodruff RD, Zagoria RJ, Hall MC. Microwave ablation of renal parenchymal tumors before nephrectomy: phase I study. AJR Am J Roentgenol. 2007;188:1212-1214.

9. Enneking WF. A system of staging musculoskeletal neoplasms. Clin Orthop Relat Res. 1986;204:9-24.

10. Enneking WF, Dunham W, Gebhardt MC, Malawar M, Pritchard DJ. A system for the functional evaluation of reconstructive procedures after surgical treatment of tumors of the musculoskeletal system. Clin Orthop Relat Res. 1993;286:241-246.

11. Fan QY, Ma BA, Zhou Y, Zhang MH, Hao XB. Bone tumors of the extremities or pelvis treated by microwave-induced hyperthermia. Clin Orthop Relat Res. 2003;406:165-175.

12. Gillespy T 3rd, Manfrini M, Ruggieri P, Spanier SS, Pettersson $\mathrm{H}$, Springfield DS. Staging of intraosseous extent of osteosarcoma: correlation of preoperative CT and MR imaging with pathologic macroslides. Radiology. 1988;167:765-767.

13. Jesus-Garcia R, Seixas MT, Costa SR, Petrilli AS, Laredo Filho J. Epiphyseal plate involvement in osteosarcoma. Clin Orthop Relat Res. 2000;373:32-38.

14. Jeys L, Matharu GS, Nandra RS, Grimer RJ. Can computer navigation-assisted surgery reduce the risk of an intralesional margin and reduce the rate of local recurrence in patients with a tumour of the pelvis or sacrum? Bone Joint J. 2013;95:1417-1424.

15. Kumta SM, Chow TC, Griffith J, Li CK, Kew J, Leung PC. Classifying the location of osteosarcoma with reference to the epiphyseal plate helps determine the optimal skeletal resection in limb salvage procedures. Arch Orthop Trauma Surg. 1999;119:327-331.

16. Lewis VO. Limb salvage in the skeletally immature patient. Curr Oncol Rep. 2005;7:285-292.

17. Li J, Shi L, Chen GJ. Image navigation assisted joint-saving surgery for treatment of bone sarcoma around knee in skeletally immature patients. Surg Oncol. 2014;23:132-139.
18. Li J, Wang Z, Guo Z, Chen GJ, Li SW, Pei GX. The use of massive allograft with intramedullary fibular graft for intercalary reconstruction after resection of tibial malignancy. $J$ Reconstr Microsurg. 2011;27:37-46.

19. Li J, Wang Z, Guo Z, Chen GJ, Yang M, Pei GX. Irregular osteotomy in limb salvage for juxta-articular osteosarcoma under computer-assisted navigation. J Surg Oncol. 2012;106:411-416.

20. Manfrini M, Gasbarrini A, Malaguti C, Ceruso M, Innocenti M, Bini S, Capanna R, Campanacci M. Intraepiphyseal resection of the proximal tibia and its impact on lower limb growth. Clin Orthop Relat Res. 1999;358:111-119.

21. Mankin HJ, Springfield DS, Gebhardt MC, Tomford WW. Current status of allografting for bone tumors. Orthopedics. 1992;15:1147-1154.

22. Morgan HD, Cizik AM, Leopold SS, Hawkins DS, Conrad EU. Survival of tumor megaprostheses replacements about the knee. Clin Orthop Relat Res. 2006;450:39-45.

23. Muscolo DL, Ayerza MA, Aponte-Tinao LA, Ranalletta M. Partial epiphyseal preservation and intercalary allograft reconstruction in high-grade metaphyseal osteosarcoma of the knee. J Bone Joint Surg Am. 2004;86:2686-2693.

24. Simon CJ, Dupuy DE, Mayo-Smith WW. Microwave ablation: principles and applications. Radiographics. 2005;25(suppl 1):S69-S83.

25. Simon MA, Bos GD. Epiphyseal extension of metaphyseal osteosarcoma in skeletally immature individuals. $J$ Bone Joint Surg Am. 1980;62:195-204.

26. Tsuchiya H, Abdel-Wanis ME, Tomita K. Biological reconstruction after excision of juxta-articular osteosarcoma around the knee: a new classification system. Anticancer Res. 2006;26:447453.

27. Wong KC, Kumta SM. Joint-preserving tumor resection and reconstruction using image-guided computer navigation. Clin Orthop Relat Res.2013;471:762-773.

28. Yoshida Y, Osaka S, Tokuhashi Y. Analysis of limb function after various reconstruction methods according to tumor location following resection of pediatric malignant bone tumors. World $J$ Surg Oncol. 2010;8:39. 